\title{
miR-185 enhances the inhibition of proliferation and migration induced by ionizing radiation in melanoma
}

\author{
JINPENG HE ${ }^{1,2^{*}}$, NING TIAN ${ }^{1,3^{*}}$, YANLI YANG ${ }^{4}$, LIANGLIANG JIN ${ }^{4}$, XIU FENG $^{1,3}$, \\ JUNRUI HUA ${ }^{1,2}$, SULAN LIN ${ }^{1,5}$, BING WANG ${ }^{1,5}$, HE LI $^{1,5}$ and JUFANG WANG ${ }^{1,2}$ \\ ${ }^{1}$ Gansu Key Laboratory of Space Radiobiology; ${ }^{2}$ Key Laboratory of Heavy Ion Radiation Biology and Medicine of \\ Chinese Academy of Sciences, Institute of Modern Physics, Chinese Academy of Sciences; ${ }^{3}$ School of Pharmacy, \\ Lanzhou University, Lanzhou, Gansu 730000; ${ }^{4}$ Department of Pathology, Lanzhou General Hospital, \\ Lanzhou Command of the Chinese People's Liberation Army, Lanzhou, Gansu 730050; \\ ${ }^{5}$ University of Chinese Academy of Sciences, Beijing 100049, P.R. China
}

Received January 5, 2016; Accepted December 2, 2016

DOI: 10.3892/ol.2017.5699

\begin{abstract}
Melanoma is an aggressive malignancy that is increasingly common and exhibits a poor patient survival rate. Radiotherapy is the primary option for patients with melanoma, particularly those who are not candidates for surgery; however, the therapeutic effect is limited due to the relative radioresistance of melanoma to ionizing radiation (IR). It has been reported that microRNAs (miRNAs) serve a vital role in determining the radiosensitivity of tumors; however, little is known concerning the radiosensitization of melanoma using miRNA. In the present study, the radiosensitization effect of miRNA 185 (miR-185), which has been demonstrated to reduce renal cancer radioresistance, was investigated in B16 cells, a skin melanoma cell line derived from C57/BL mice, was investigated. Cell proliferation and scratch wound healing assays were used to determine the proliferative and migratory abilities of B16 cells. Annexin V/propidium iodide double staining was used to determine the apoptosis induced by IR. A tumor formation assay was performed to determine the radiosensitization effect of miR-185 on melanoma cells in vivo. Proliferation marker protein Ki-67, and hematoxylin and eosin staining were used to assess the proliferative activity and histological changes, respectively. The results of the present study demonstrated that miR-185 suppresses cellular proliferation and migration, and enhances IR-induced apoptosis, and the inhibition of proliferation and migration, in vitro
\end{abstract}

Correspondence to: Dr Jufang Wang, Gansu Key Laboratory of Space Radiobiology, Institute of Modern Physics, Chinese Academy of Sciences, 509 Nanchang Road, Lanzhou, Gansu 730000, P.R. China

E-mail: jufangwang@impcas.ac.cn

*Contributed equally

Key words: melanoma, radiosensitivity, microRNA, miR-185 and in vivo, which provides an insight into understanding the radiosensitization of melanoma using miRNA.

\section{Introduction}

Melanoma is a metastatic and fatal type of cancer, for which the median 5-year survival rate is $<5 \%$ following metastasis $(1,2)$. The global incidence of melanoma has increased more rapidly compared with that of other malignancies (3). Therapeutic options remain limited. Although melanoma is considered to be a relatively radioresistant tumor, radiation therapy is important in the treatment of melanoma, particularly in patients with central nervous system metastases (4). In addition, enhancement of tumor radiosensitivity with a radiosensitizer is an efficient strategy to improve the outcome of radiotherapy (5).

microRNAs (miRNAs) are a class of small endogenous RNAs that function in mRNA degradation and the inhibition of mRNA translation at the post-transcriptional level. A previous study suggested an important role for miRNAs in the mediation of tumor cell sensitivity to ionizing radiation (IR) by efficiently influencing DNA damage repair, cell cycle checkpoints, apoptosis, radio-related signal transduction pathways and the tumor microenvironment (6). In melanoma, miRNA 21 (miR-21) and miR-let-7b have been demonstrated to be related to the cellular radioresistance $(7,8)$. However, the underlying molecular mechanisms by which miRNAs regulate cellular sensitivity to IR remain unclear.

Previous studies have demonstrated that miR-185, a key miRNA in cancer, is involved in the regulation of various cellular processes, including proliferation, cell cycle, invasion and migration (9-12), and promotes cellular sensitivity to IR in human renal cancer cells by targeting ataxia telangiectasia- and Rad3-related (ATR) (13), an important sensor and transducer, as well as ataxia telangiectasia mutated, in the DNA damage response signaling pathway (14). By contrast, miR-185 is able to reduce cellular resistance to chemotherapeutic drugs in gastric cancer and ovarian cancer by targeting apoptosis repressor with caspase recruitment domain, or DNA methyltransferase $1(15,16)$. These results suggest that miR-185 serves an integral role in the cellular response to radiotherapy 
and chemotherapy. Therefore, it is hypothesized that miR-185 may be involved in the regulation of cellular radiosensitivity in melanoma.

In the present study, the function of miR-185 in the mediation of cellular sensitivity to IR in melanoma was investigated. Results suggested that miR-185 has a tumor suppressor role in B16 cells via suppression of cellular proliferation and migration, and that modulation of miR-185 levels may alter the radiosensitivity of melanoma in vitro and in vivo.

\section{Materials and methods}

Cell culture. The mouse melanoma cell line B16 was purchased from the Shanghai Institute for Biological Sciences (Shanghai, China). Cells were cultured at $37^{\circ} \mathrm{C}$ under $5 \% \mathrm{CO}_{2}$ in RPMI-1640 medium (Gibco; Thermo Fisher Scientific, Inc., Waltham, MA, USA) supplemented with $10 \%$ fetal bovine serum (FBS; HyClone; GE Healthcare Life Sciences, Logan, UT, USA), 100 units $/ \mathrm{ml}$ penicillin and $100 \mathrm{mg} / \mathrm{ml}$ streptomycin.

Cell transfection. A total of $1 \times 10^{5}$ cells were seeded into 12-well plates and cultured for $24 \mathrm{~h}$, prior to transfection with miR-185 precursor (pre-miR-185; cat. no. AM17100) or the negative control (pre-neg; cat. no. AM17100) (both Ambion; Thermo Fisher Scientific, Inc.) at 40-60\% confluence using Lipofectamine $^{\mathrm{TM}} 2000$ (Invitrogen; Thermo Fisher Scientific, Inc.). The final concentration of the miRNA duplex was $30 \mathrm{mM}$. The medium was replaced with fresh culture medium $5 \mathrm{~h}$ following transfection.

Cell proliferation curves. Cells $\left(1 \times 10^{5}\right)$ were seeded into 12 -well plates and cultured for $24 \mathrm{~h}$. Following transfection with miRNA duplex, cells were exposed to 0 or 4 Gy X-rays using a Faxitron RX-650 instrument (Faxitron Bioptics, LLC, Tucson, AZ, USA) at a dose rate of $0.8 \mathrm{~Gy} / \mathrm{min}(100 \mathrm{keV}$, $5 \mathrm{~mA}$ ). Cells were counted 0, 24, 48 and $72 \mathrm{~h}$ following X-ray exposure using a Coulter counter (Beckman Coulter, Inc., Brea, CA, USA) and the experiment was carried out three times for construction of proliferation curves.

Cell migration assay. A scratch wound healing assay was carried out to estimate the cellular migration ability as described previously (17). A total of $2 \times 10^{5}$ exponentially growing cells were seeded into a $35 \mathrm{~mm}$ dish and incubated for $24 \mathrm{~h}$ at $37^{\circ} \mathrm{C}$. Following transfection with $30 \mathrm{mM}$ pre-miR-185 or pre-neg, cells were exposed to 0 or 4 Gy X-rays and scratched with $200 \mu \mathrm{l}$ pipette tips immediately. Dishes were washed twice with PBS and fresh culture medium was added prior to re-incubation for $18 \mathrm{~h} 37^{\circ} \mathrm{C}$. Wound closure was observed and images were captured using a Leica DMI6000 B inverted microscope (Leica Microsystems GmbH, Wetzlar, Germany) at 0 and $18 \mathrm{~h}$.

Colony formation assay. Cells were harvested by trypsinization and resuspended in RPMI-1640 medium supplemented with $10 \%$ FBS. An appropriate number of cells was plated into a $60 \mathrm{~mm}$ dish to produce $\sim 50-100$ colonies. Following incubation for 8 days, cells were fixed with $75 \%$ ethanol for $5 \mathrm{~min}$ and stained with $0.5 \%$ crystal violet for $10 \mathrm{~min}$ at room temperature. Colonies containing $>50$ cells were counted as survivors, at least three parallel dishes were scored for each treatment, and each experiment was conducted at least three times independently. The survival fraction (SF) was calculated as follows: $\mathrm{SF}=\mathrm{PE} / \mathrm{PE} 0$. In this calculate $\mathrm{PE}$ respresents the plating efficiency of the irradiated cells and PE0 represents the plating efficiency of the control cells.

Cell apoptosis assay. Cells $\left(2 \times 10^{5}\right)$ were exposed to $4 \mathrm{~Gy}$ $\mathrm{X}$-rays immediately following transfection with miRNA duplex, and were harvested $48 \mathrm{~h}$ following irradiation. Cell apoptosis was determined using an annexin V-fluorescein isothiocyanate (FITC) kit (cat. no. 130-092-052; Miltenyi Biotec, Inc., Auburn, CA, USA), according to the manufacturer's protocol. Cells were stained with $0.5 \mu \mathrm{g} / \mathrm{ml}$ annexin $\mathrm{V}$-FITC and $5 \mu \mathrm{g} / \mathrm{ml}$ PI for $30 \mathrm{~min}$ at room temperature. Cell apoptosis was analyzed immediately following staining using a FACSCalibur flow cytometer (BD Biosciences, Franklin Lakes, NJ, USA). The total apoptotic rate was calculated as the sum of the early apoptotic rate and the late apoptotic rate. At least 10,000 gated events were acquired from each sample and each experiment was performed in triplicate.

Tumor formation assay. Two-month-old male Kunming mice and C57/BL6 mice weighing $20 \mathrm{~g}$ were obtained from Lanzhou University Laboratory Animal Center (Lanzhou, Gansu, China). All mice were had ad libitum access to standard laboratory rodent feed and water. Mice were acclimatized for 1 week to standard conditions of a temperature of $\sim 23^{\circ} \mathrm{C}$, humidity of $\sim 60 \%$ and a $12 \mathrm{~h} \mathrm{light/dark} \mathrm{cycle.} \mathrm{Exponentially}$ growing B16 cells $\left(2 \times 10^{5}\right.$ in $200 \mu 1$ normal saline) were injected subcutaneously into the groins of Kunming mice $(n=6)$ or C57/BL6 mice $(n=9)$. Following formation of tumors, $10 \mu \mathrm{g}$ miRNA duplex was transfected into tumor cells using in vivo-jetPEI ${ }^{\circledR}$ (Polyplus-transfection, Illkirch, France) according to the manufacturer's protocol (day 1), and $24 \mathrm{~h}$ following transfection (day 2) tumors were exposed to 0 (Kunming mice) or 4 (C57/BL6 mice) Gy X-rays with the rest of the mice shielded; these treatments were performed once every 2 days three times. Each day, the length and width of tumor was measured over the skin using an external caliper and the tumor volume was calculated using the formula: volume $\left(\mathrm{mm}^{3}\right)=$ length $(\mathrm{mm}) \mathrm{x}$ width ${ }^{2}\left(\mathrm{~mm}^{2}\right) / 2$. The mice were sacrificed by cervical dislocation 2 days following the third irradiation treatment (day 8). Tumors were dissected, weighed, images captured using a digital camera and specimens fixed for pathological analysis. The animal procedures used in the present study were approved by the Institutional Animal Care and Use Committee of Lanzhou University.

Immunohistochemistry. The isolated tumor samples were fixed at room temperature with $4 \%$ paraformaldehyde in PBS for $30 \mathrm{~min}$, then dehydrated in 70, 80, 90, 95 and 100\% alcohol in turn for $30 \mathrm{~min}$ each, and finally embedded in paraffin. The paraffin sections were collected on slides and stained with hematoxylin and eosin (H\&E; cat. no. C0105; Beyotime Institute of Biotechnology, Haimen, China) for $20 \mathrm{~min}$ at room temperature to verify histological changes. In addition, 4- $\mu$ m-thick paraffin sections were prepared for immunohistochemistry experiments. The sections were deparaffinized with xylene for $20 \mathrm{~min}$, rehydrated with alcohol $(100 \%$ alcohol for 
$\mathbf{A}$

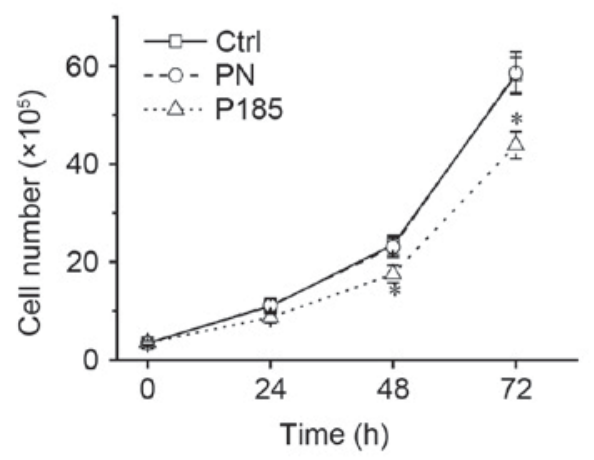

P185

B

Ctrl

PN
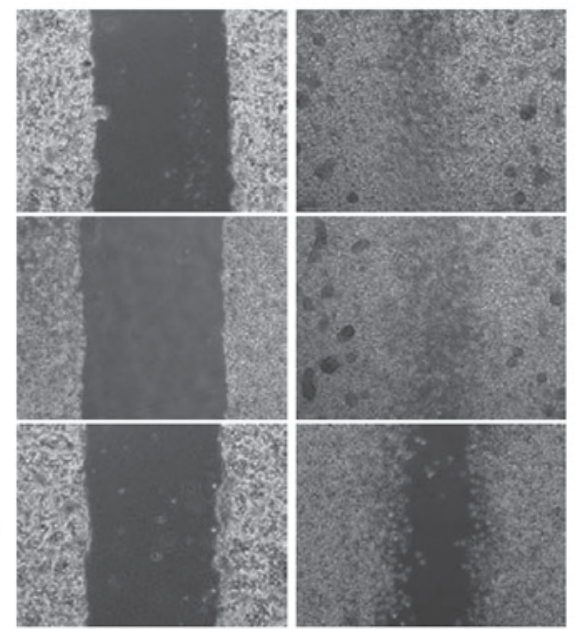

C

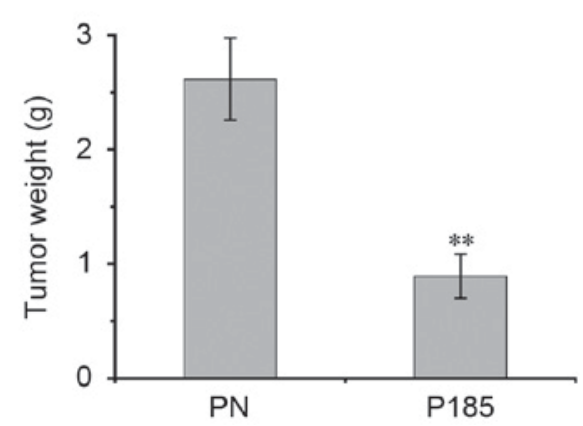

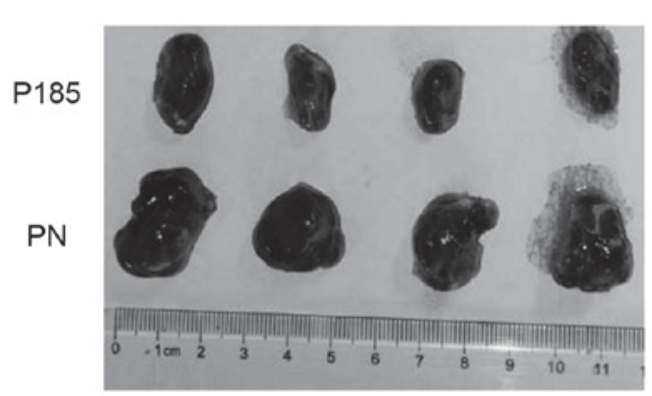

Figure 1. miR-185 suppresses the proliferation and migration of B16 cells. (A) Proliferation curves of B16 cells following transfection with PN or P185. (B) Representative images of scratch wound healing assay. Confluent cells were scratched using pipette tips immediately following transfection and irradiation; photomicrographs (magnification, x50) were taken at 0 and $18 \mathrm{~h}$ respectively. (C) The effect of miR-185 on the development of tumors formed by B16 cells in Kunming mice $(\mathrm{n}=6)$. Tumors were isolated, weighed and imaged on the 15th day following subcutaneous injection of B16 cells into the groins. " $\mathrm{P}<0.05$, ${ }^{* *} \mathrm{P}<0.01$ vs. PN. miR-185, microRNA 185; Ctrl, untreated cells; PN, pre-neg-transfected cells; P185, pre-miR-185-transfected cells.

10 min each, 95\% alcohol for $2 \mathrm{~min}$ and $70 \%$ alcohol for $2 \mathrm{~min}$ ) and washed briefly in distilled water. Endogenous peroxidase activity was quenched using 3\% hydrogen peroxide in methanol, and antigen retrieval was carried out in $10 \mathrm{mM}$ citrate buffer using a microwave. The slides were blocked with 5\% bovine serum albumin (cat. no. ST023; Beyotime Institute of Biotechnology) for $1 \mathrm{~h}$ and incubated with primary anti-proliferation marker protein Ki-67 (Ki-67) antibody (1:200; cat. no. 12202; Cell Signaling Technology, Inc., Danvers, MA, USA) for $2 \mathrm{~h}$ at room temperature. Following a 1-h incubation with goat anti-rabbit horseradish peroxidase-conjugated secondary antibody (1:1,000; cat. no. SC-3837; Santa Cruz Biotechnology Inc., Dallas, TX, USA) at room temperature, color was detected with Diamobenzidine Horseradish Peroxidase Color Development kit (cat. no. P0202; Beyotime Institute of Biotechnology). Ki-67-positive cells were counted under a light microscope and at least 1,000 cells were scored for each sample.

Statistical analysis. Experiments were performed in triplicate and results are presented as the mean \pm standard deviation. The statistical significance of the results was determined by Student's $t$-test using Microsoft Excel 2007 software (Microsoft Corporation, Redmond, WA, USA). $\mathrm{P}<0.05$ was considered to indicate a statistically significant difference.

\section{Results}

miR-185 functions as a tumor suppressor in melanoma B16 cells. It is well-known that melanoma is an aggressive cancer with increased proliferative ability (18). Previous studies have revealed that miR-185 functions as a tumor suppressor in numerous types of cancer $(9,19)$. In the present study, B16 cells, a melanoma cell line derived from C57 mice (20), were employed to determine whether miR-185 has tumor suppressive effects on melanoma.

miR-185 levels in B16 cells were increased following transfection with exogenous pre-miR-185, and the changes in the cellular proliferation and migration abilities were evaluated. As presented in Fig. 1A, the proliferation rate of cells transfected with pre-miR-185 was significantly decreased compared with cells transfected with pre-neg $(\mathrm{P}=0.012)$, indicating that miR-185 overexpression in B16 cells suppressed cellular proliferation. In addition, the cellular motility was evaluated in vitro using a scratch wound healing assay. The untreated and pre-neg-overexpressing cells migrated more $18 \mathrm{~h}$ following scratching compared with the cells transfected with pre-miR-185 (Fig. 1B), indicating that miR-185 markedly suppressed the migratory ability of B16 cells.

The role of miR-185 in proliferation inhibition was confirmed using an in vivo tumor formation assay. The volume 
$\mathbf{A}$

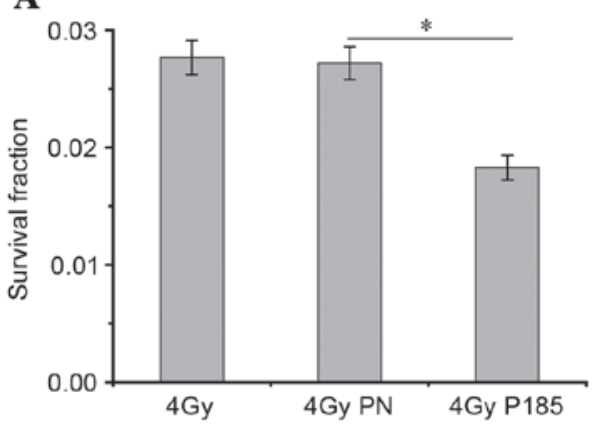

C
B

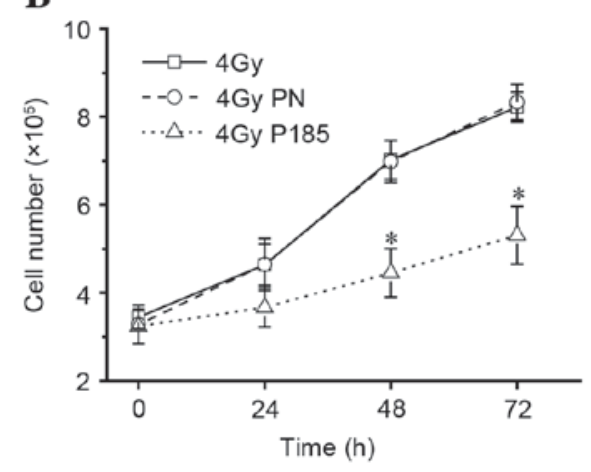

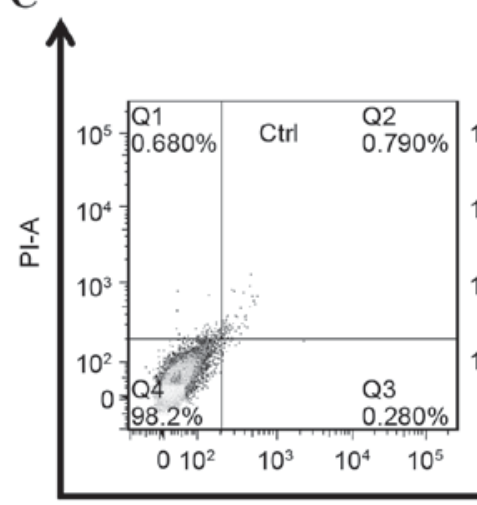

$010^{2}$

-

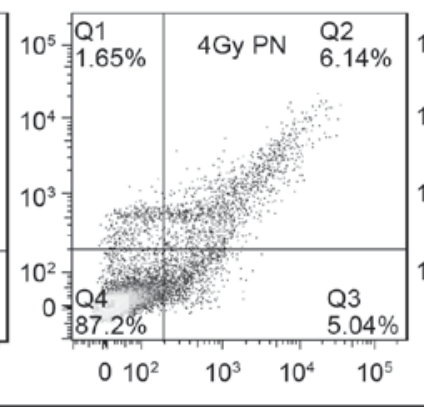

FITC-A

\section{D}

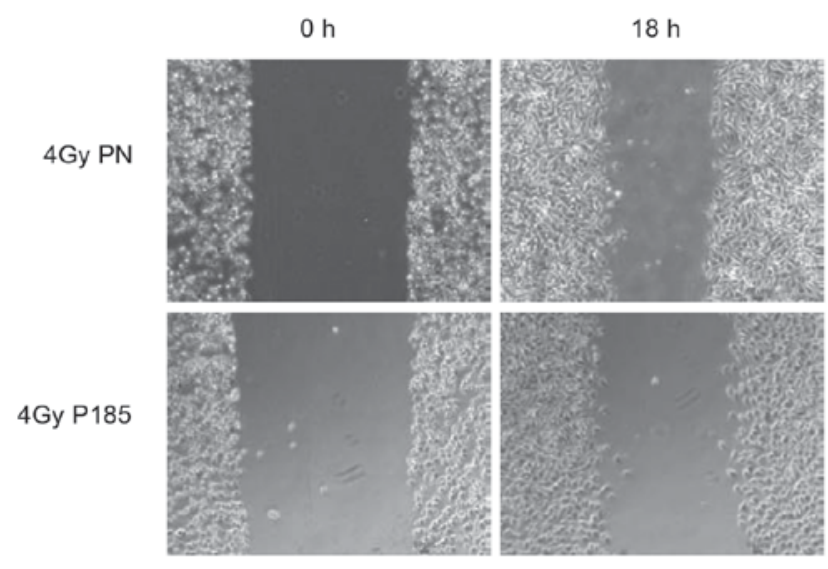

Figure 2. miR-185 is a radiosensitizer of B16 cells in vitro. (A) Colony formation assay of pre-neg- or pre-miR-185-overexpressing B16 cells exposed to 4 Gy X-rays. (B) Proliferation curves of B16 cells transfected with miRNA duplex following 4 Gy X-ray treatment. (C) Annexin V/propidium iodide double staining assay in B16 cells transfected with pre-neg or pre-miR-185, $48 \mathrm{~h}$ following $4 \mathrm{~Gy}$ of X-ray irradiation. (D) Representative images (magnification, $\mathrm{x} 50$ ) of scratch wound healing assay. ${ }^{*} \mathrm{P}<0.05,{ }^{* *} \mathrm{P}<0.01$ vs. PN. miR-185, miRNA 185; miRNA, microRNA; PN, pre-neg-transfected cells; P185, pre-miR-185-transfected cells; Q, quadrant; PI, propidium iodide; A, annexin; FITC, fluorescein isothiocyanate.

of tumor formed by B16 cells transfected with pre-miR-185 was decreased compared with that transfected with pre-neg, and the mean weight of tumors significantly decreased from $2.62 \pm 0.36$ to $0.89 \pm 0.20 \mathrm{~g}(\mathrm{P}=0.002$; Fig. 1C). These results indicate that miR-185 exhibits tumor suppressor functions in melanoma in vitro and in vivo.

miR-185 enhances cellular sensitivity to IR in vitro. The authors previously demonstrated that overexpression of miR-185 may enhance IR-induced apoptosis and proliferation inhibition through repression of the ATR signaling pathway (12). Therefore, it was assessed whether the expression level of miR-185 was associated with the cellular sensitivity of B16 cells to IR. As presented in Fig. 2A, the survival fraction of colonies in the pre-neg-transfected cells following treatment with 4 Gy X-rays was $2.72 \pm 0.15 \%$, which was significantly decreased to $1.82 \pm 0.10 \%$ in $\mathrm{miR}-185$-overexpressing cells $(\mathrm{P}=0.032)$.

It was identified that $\mathrm{B} 16$ cells exhibited $\mathrm{G}_{1}$ cell cycle arrest (data not shown) and suppression of proliferation following 4 Gy X-ray irradiation (Fig. 2B, compared with non-irradiated control in Fig. 1A). Notably, overexpression of miR-185 significantly enhanced the effect of IR-induced inhibition of proliferation compared with overexpression of pre-neg ( $\mathrm{P}=0.014$; Fig. 2B) by promoting apoptosis (Fig. 2C). The total apoptotic rate in pre-neg-overexpressing cells $48 \mathrm{~h}$ following 


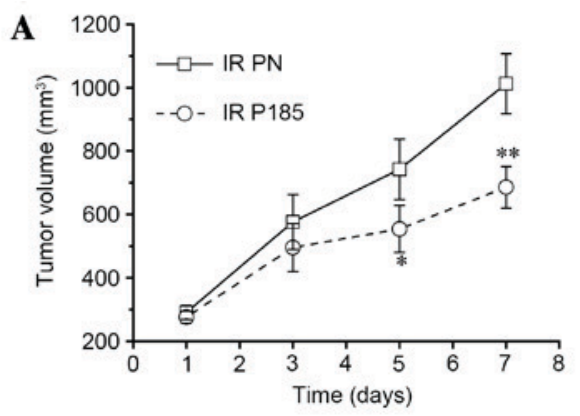

B
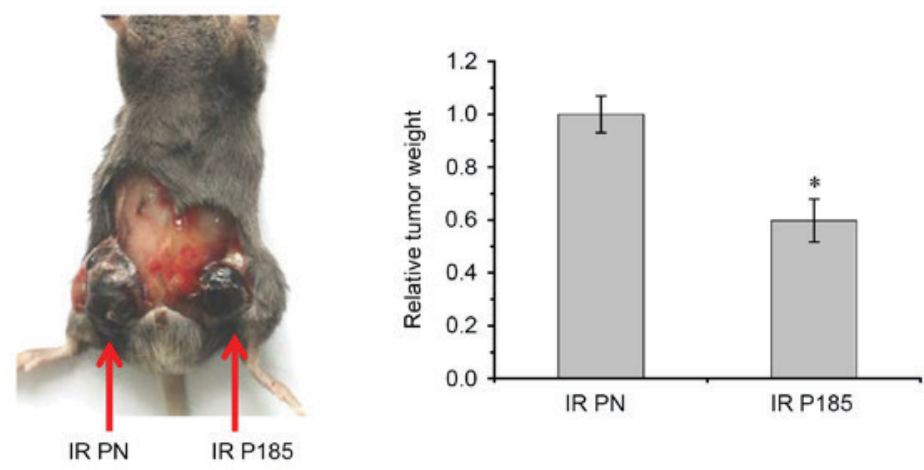

C

Ctrl

IR PN

IR P185
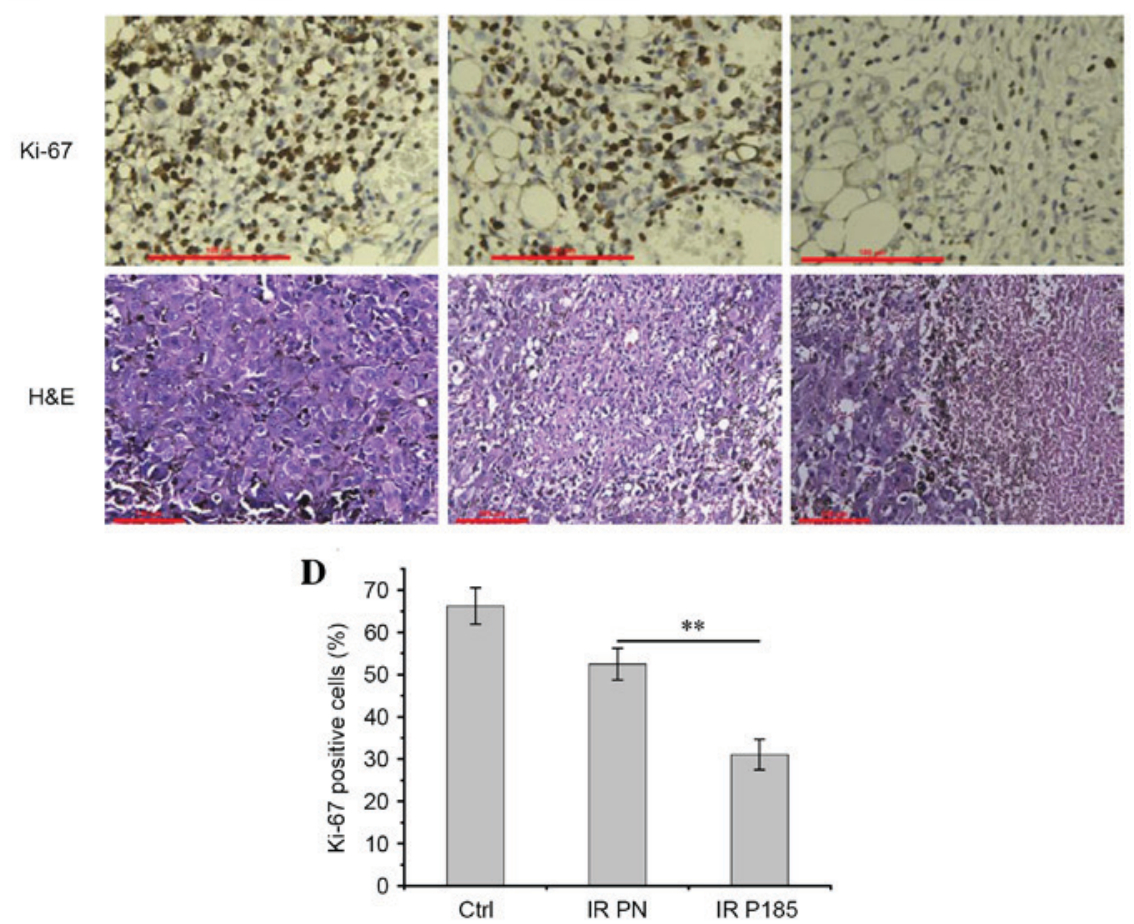

Figure 3. Effect of miR-185 on tumor radiotherapy outcome. B16 cells were injected subcutaneously into the groins of C57/BL6 mice. Following formation of tumors, mice $(n=9)$ were selected at random on day 1 . miRNA duplex were transfected into tumors on days 1,3 and 5 , whereas tumors were locally exposed to 4 Gy of X-rays on days 2, 4 and 6 independently. (A) Change in tumor volume over the treatment period. (B) Representative mouse with tumors captured on day 8 and relative tumor weight (IR P185 vs. IR PN). (C) Representative images of immunohistochemistry for Ki-67 (magnification, x400) and H\&E staining (magnification, x200) in tumor tissues. (D) The allograft tumors removed from C57/BL6 mice were analyzed using immunohistochemistry for expression of Ki-67. ${ }^{*} \mathrm{P}<0.05,{ }^{* *} \mathrm{P}<0.01$ vs. IR PN. Scale bars, $100 \mu \mathrm{m}$. miR-185, miRNA 185; miRNA, microRNA; IR, ionizing radiation; PN, pre-neg-transfected cells; P185, pre-miR-185-transfected cells; Ctrl, control; Ki-67, proliferation marker protein Ki-67; H\&E, hematoxylin and eosin.

4 Gy X-ray irradiation was $12.64 \pm 2.46 \%$, whereas that in pre-miR-185-overexpressing cells increased to $18.46 \pm 1.13 \%$. In addition, miR-185 exacerbated the IR-induced decrease in migratory ability (Fig. 2D, compared with non-irradiated control in Fig. 1B). These results suggest that miR-185 may regulate cellular radiosensitivity in vitro.
miR-185 enhances IR-induced homograft tumor growth inhibition. Following the observed effect of miR-185 on the mediation of cellular sensitivity to IR in vitro, the potential role of this miRNA in the improvement of tumor radiosensitivity was evaluated in vivo. Homologous subcutaneous cancer models were established through inoculation of B16 
cells into the groins of C57/BL mice, and miRNA duplex (pre-miR-185 and pre-neg) was directly transfected into tumors when the tumor size was $\sim 0.8 \mathrm{~cm}$. Tumors were locally exposed to $4 \mathrm{~Gy} \mathrm{X}$-rays $24 \mathrm{~h}$ following transfection and these treatments were carried out three times. The length and width of tumors were measured each day following the first transfection (marked as day 1), and the proliferation curves demonstrated that the tumor growth rate was significantly reduced in miR-185-overexpressing cells following fractionated treatment with $\mathrm{X}$-rays three times $(\mathrm{P}=0.006$; Fig. 3A), suggesting that miR-185 enhances IR-induced tumor growth inhibition.

Tumors were isolated and fixed 2 days following the third irradiation (day 8), and, consistent with the above results, tumors formed by B16 cells transfected with pre-miR-185 had a significantly decreased weight and decreased size compared with the pre-neg-transfected control cells ( $\mathrm{P}=0.026$; Fig. 3B). The immunohistochemistry for Ki-67 expression in tumor sections was examined, and it was identified that the immunoreactivity for Ki-67 expression in the pre-neg-overexpressing cells was markedly more intense than in the miR-185-overexpressing cells (Fig. 3C). Histological observation using H\&E staining identified that the tumor cells following IR treatment in the pre-neg-overexpressing group became heterogeneous with large nuclei, irregular nuclear shapes and nuclear condensation, whereas the miR-185-overexpressing cells exhibited increased catastrophic lesions and clear cell death (Fig. 3C). The proportion of Ki-67-positive cells in the IR-treated pre-neg-overexpressing group was $52.47 \pm 3.77 \%$, which was significantly decreased to $31.05 \pm 3.61 \%$ in the IR-treated pre-miR-185-overexpressing group $(\mathrm{P}=0.003$; Fig. 3D). These data demonstrate that miR-185 promotes cellular radiosensitivity in vivo.

\section{Discussion}

miRNA is a robust molecular tool that has potential in the development of future therapeutic technologies. An increasing number of underlying molecular mechanisms for the radiosensitization effect of miRNAs have been elucidated (21-24). However, the underlying molecular mechanism in malignant melanoma remains unclear. The authors previously demonstrated that miR-185 overexpression markedly increased radiosensitization of renal carcinoma cells (13). In the present study, the enhancement of radiosensitivity in melanoma cells was investigated using miR-185 and it was observed that miR-185 significantly enhanced IR-induced cell death in vitro and in vivo, suggesting that it exhibited a radiosensitization function in malignant melanoma.

miR-185 induces cell cycle arrest and apoptosis via direct regulation of homeobox protein Six 1, transforming protein RhoA and cell division control protein 42 (CDC42) in human cancer $(9,25)$. Furthermore, it has been reported that miR-185 suppresses proliferation, invasion and migration in numerous types of cancer, including glioma (26), prostate cancer (11), gastric cancer (27), colon cancer (28) and hepatocarcinoma (19). Emerging evidence suggests that miR-185 serves important roles in modulating the growth of melanoma xenografts implanted in severe combined immunodeficiency-non-obese diabetic mice (29). However, to the best of our knowledge, the present study is the first to demonstrate that miR-185 inhibits cellular proliferation and migration in melanoma cells, suggesting that miR-185 may be an effective target for the treatment of various types of cancer, including melanoma.

Although systemic therapy is the mainstay of treatment for melanoma, which has historically been regarded as a relatively radioresistant tumor, fractionated and stereotactic radiation therapy are effective options for certain patients with melanoma, particularly those with brain metastases (30). Walston et al (31) reported IR-induced miRNA deregulation in melanoma. It was identified that the miRNA profiles are significantly different in pre- and post-irradiated cells at 5 days in multiple melanoma cell lines and suggested that miRNAs with differential expression may be associated with resistance to IR. The study led to the development of research on sensitizing melanoma to IR via miRNAs, and miR-21 and let-7b were identified as important factors in response to IR in melanoma $(7,8)$. Therefore, it is conceivable that more miRNAs may be involved in regulating the cellular sensitivity to IR in melanoma.

It has been demonstrated that miR-185 and miR-185-3p may decrease the radioresistance in human renal carcinoma and nasopharyngeal carcinoma, respectively, by targeting ATR and protein WNT2B $(13,32)$. In silico prediction models were used to identify potential binding sites for miR-185 in the mRNA of ATR and WNT2B in mice; however, no putative site was predicted. In addition, it was identified that a side of B16 cells presented $\mathrm{G}_{1}$ cell cycle arrest following IR exposure, whereas IR induced $\mathrm{G}_{2}$ cell cycle arrest in the non-side population cells (33). These results suggested the presence of another signaling pathway regulated by miR-185 in melanoma. Target prediction using bioinformatics software miRDB and microRNA. org demonstrated that $\mathrm{CDC} 42$ is a potential target of mouse miR-185, which is essential for $\mathrm{G}_{1}$ cell cycle arrest, proliferation and invasion in cancer cells (34-37). In addition, miR-185 has been identified to target CDC42 in human colorectal cells (9). Therefore, further evidence is required to clarify the underlying molecular mechanism through which miR-185 mediates the radiosensitivity of melanoma cells by targeting CDC42.

In conclusion, the present study demonstrates an important role for miR-185 in regulating the development and radiosensitivity of B16 melanoma cells. It was demonstrated that miR-185 suppresses the proliferation and migration of B16 cells in vitro and in vivo. It was further demonstrated that miR-185 overexpression reduces the survival of B16 cells and of its homograft tumors exposed to X-rays. Therefore, these findings may lead to the development of miRNA-based-drugs to sensitize melanoma to radiotherapy.

\section{Acknowledgements}

The present study was supported by grants from the National Nature Science Foundation of China (grant nos. 31270895, 11405232 and 31400723).

\section{References}

1. Miller AJ and Mihm MC Jr: Melanoma. N Engl J Med 355: 51-65, 2006. 
2. Rebecca V: Rapid growth in melanoma rate. JAMA 314: 332 , 2015.

3. Jemal A, Siegel R, Ward E, Hao Y, Xu J and Thun MJ: Cancer statistics, 2009. CA Cancer J Clin 59: 225-249, 2009.

4. Bhatia S, Tykodi SS and Thompson JA: Treatment of metastatic melanoma: An overview. Oncology (Williston Park) 23: 488-496, 2009.

5. Lee IJ and Seong J: Radiosensitizers in hepatocellular carcinoma. Semin Radiat Oncol 21: 303-311, 2011.

6. Zhao L, Bode AM, Cao Y and Dong Z: Regulatory mechanisms and clinical perspectives of miRNA in tumor radiosensitivity. Carcinogenesis 33: 2220-2227, 2012.

7. Jiang L, Lv X, Li J, Li J, Li X, Li W and Li Y: The status of microRNA-21 expression and its clinical significance in human cutaneous malignant melanoma. Acta Histochem 114: 582-588, 2012.

8. Zhou Y, Zhang L, Fan J, Jia R, Song X, Xu X, Dai L, Zhuang A, Ge $S$ and Fan X: Let-7b overexpression leads to increased radiosensitivity of uveal melanoma cells. Melanoma Res 25: 119-126, 2015.

9. Liu M, Lang N, Chen X, Tang Q, Liu S, Huang J, Zheng Y and Bi F: miR-185 targets RhoA and Cdc42 expression and inhibits the proliferation potential of human colorectal cells. Cancer Lett 301: 151-160, 2011

10. Takahashi Y, Forrest AR, Maeno E, Hashimoto T, Daub CO and Yasuda J: MiR-107 and MiR-185 can induce cell cycle arrest in human non small cell lung cancer cell lines. PLoS One 4: e6677, 2009.

11. Qu F, Cui X, Hong Y, Wang J, Li Y, Chen L, Liu Y, Gao Y, Xu D and Wang Q: MicroRNA-185 suppresses proliferation, invasion, migration, and tumorigenicity of human prostate cancer cells through targeting androgen receptor. Mol Cell Biochem 377: 121-130, 2013

12. Akçakaya P, Ekelund S, Kolosenko I, Caramuta S, Ozata DM Xie $\mathrm{H}$, Lindforss $\mathrm{U}$, Olivecrona $\mathrm{H}$ and Lui WO: miR-185 and miR-133b deregulation is associated with overall survival and metastasis in colorectal cancer. Int J Oncol 39: 311-318, 2011

13. Wang J, He J, Su F, Ding N, Hu W, Yao B, Wang W and Zhou G: Repression of ATR pathway by miR-185 enhances radiation-induced apoptosis and proliferation inhibition. Cell Death Dis 4: e699, 2013.

14. Zhou BB and Elledge SJ: The DNA damage response: Putting checkpoints in perspective. Nature 408: 433-439, 2000.

15. Li Q, Wang JX, He YQ, Feng C, Zhang XJ, Sheng JQ and Li PF MicroRNA-185 regulates chemotherapeutic sensitivity in gastric cancer by targeting apoptosis repressor with caspase recruitment domain. Cell Death Dis 5: e1197, 2014.

16. Xiang Y, Ma N, Wang D, Zhang Y, Zhou J, Wu G, Zhao R, Huang $\mathrm{H}$, Wang $\mathrm{X}$, Qiao $\mathrm{Y}$, et al: MiR-152 and miR-185 co-contribute to ovarian cancer cells cisplatin sensitivity by targeting DNMT1 directly: A novel epigenetic therapy independent of decitabine. Oncogene 33: 378-386, 2014.

17. He J, Li J, Ye C, Zhou L, Zhu J, Wang J, Mizota A, Furusawa Y and Zhou G: Cell cycle suspension: A novel process lurking in $\mathrm{G}_{2}$ arrest. Cell Cycle 10: 1468-1476, 2011.

18. Luo C, Weber CE, Osen W, Bosserhoff AK and Eichmüller SB The role of microRNAs in melanoma. Eur J Cell Biol 93: 11-22, 2014.

19. Qadir XV, Han C, Lu D, Zhang J and Wu T: miR-185 inhibits hepatocellular carcinoma growth by targeting the DNMT1/PTEN/Akt pathway. Am J Pathol 184: 2355-2364, 2014.

20. Fidler IJ: Biological behavior of malignant melanoma cells correlated to their survival in vivo. Cancer Res 35: 218-224, 1975.

21. Lal A, Pan Y, Navarro F, Dykxhoorn DM, Moreau L, Meire E, Bentwich Z, Lieberman J and Chowdhury D: miR-24-mediated downregulation of $\mathrm{H} 2 \mathrm{AX}$ suppresses DNA repair in terminally differentiated blood cells. Nat Struct Mol Biol 16: 492-498, 2009
22. Yan D, Ng WL, Zhang X, Wang $P$, Zhang Z, Mo YY, Mao H, Hao C, Olson JJ, Curran WJ and Wang Y: Targeting DNA-PKcs and ATM with miR-101 sensitizes tumors to radiation. PLoS One 5: e11397, 2010.

23. Liu Y, Xing R, Zhang X, Dong W, Zhang J, Yan Z, Li W, Cui J and $\mathrm{Lu} \mathrm{Y}$ : miR-375 targets the p53 gene to regulate cellular response to ionizing radiation and etoposide in gastric cancer cells. DNA Repair (Amst) 12: 741-750, 2013.

24. Wang XC, Zhang ZB, Wang YY, Wu HY, Li DG, Meng AM and Fan FY: Increased miRNA-22 expression sensitizes esophageal squamous cell carcinoma to irradiation. J Radiat Res 54: 401-408, 2013.

25. Imam JS, Buddavarapu K, Lee-Chang JS, Ganapathy S, Camosy C, Chen Y and Rao MK: MicroRNA-185 suppresses tumor growth and progression by targeting the Six 1 oncogene in human cancers. Oncogene 29: 4971-4979, 2010

26. Tang $\mathrm{H}$, Wang Z, Liu X, Liu Q, Xu G, Li G and Wu M: LRRC4 inhibits glioma cell growth and invasion through a miR-185-dependent pathway. Curr Cancer Drug Targets 12: 1032-1042, 2012

27. Yoon JH, Choi YJ, Choi WS, Ashktorab H, Smoot DT, Nam SW, Lee JY and Park WS: GKN1-miR-185-DNMT1 axis suppresses gastric carcinogenesis through regulation of epigenetic alteration and cell cycle. Clin Cancer Res 19: 4599-4610, 2013.

28. Lu ZJ, Lu LG, Tao KZ, Chen DF, Xia Q, Weng JJ, Zhu F, Wang XP and Zheng P: MicroRNA-185 suppresses growth and invasion of colon cancer cells through inhibition of the hypoxiainducible factor- $2 \alpha$ pathway in vitro and in vivo. Mol Med Rep 10: 2401-2408, 2014

29. Greenberg E, Hershkovitz L, Itzhaki O, Hajdu S, Nemlich Y, Ortenberg R, Gefen N, Edry L, Modai S, Keisari Y, et al: Regulation of cancer aggressive features in melanoma cells by microRNAs. PLoS One 6: e18936, 2011.

30. Dyer MA, Arvold ND, Chen YH, Pinnell NE, Mitin T, Lee EQ, Hodi FS, Ibrahim N, Weiss SE, Kelly PJ, et al: The role of whole brain radiation therapy in the management of melanoma brain metastases. Radiat Oncol 9: 143, 2014.

31. Walston SA, Gordon N, Chakravarti A and Palanichamy K MicroRNA alterations following radiation in melanoma. Cancer Res 72 (Suppl): S5052-S5052, 2012.

32. Li G, Wang Y, Liu Y, Su Z, Liu C, Ren S, Deng T, Huang D, Tian Y and Qiu Y: miR-185-3p regulates nasopharyngeal carcinoma radioresistance by targeting WNT2B in vitro. Cancer Sci 105: 1560-1568, 2014

33. Matchuk ON, Zamulaeva IA, Kovalev OA and Saenko AS Radioresistance mechanisms of side population cells in mouse melanoma cell line B16. Tsitologiia 55: 553-559, 2013 (In Russian).

34. Liu M, Lang N, Qiu M, Xu F, Li Q, Tang Q, Chen J, Chen X, Zhang S, Liu Z, et al: miR-137 targets Cdc 42 expression, induces cell cycle G1 arrest and inhibits invasion in colorectal cancer cells. Int J Cancer 128: 1269-1279, 2011.

35. Gao M, Liu L, Li S, Zhang X, Chang Z and Zhang M: Inhibition of cell proliferation and metastasis of human hepatocellular carcinoma by miR-137 is regulated by CDC42. Oncol Rep 34: 2523-2532, 2015.

36. Olson MF, Ashworth A and Hall A: An essential role for Rho, Rac, and Cdc42 GTPases in cell cycle progression through G1. Science 269: 1270-1272, 1995.

37. Wang R, Zhao N, Li S, Fang JH, Chen MX, Yang J, Jia WH, Yuan Y and Zhuang SM: MicroRNA-195 suppresses angiogenesis and metastasis of hepatocellular carcinoma by inhibiting the expression of VEGF, VAV2, and CDC42. Hepatology 58: 642-653, 2013 